\title{
Measuring Expressed Emotion: An Evaluation of the Shortcuts
}

\section{Citation}

Hooley, Jill M., and Holly A. Parker. 2006. Measuring expressed emotion: An evaluation of the shortcuts. Journal of Family Psychology 20, no. 3: 386-396.

\section{Published Version}

http://dx.doi.org/10.1037/0893-3200.20.3.386

\section{Permanent link}

http://nrs.harvard.edu/urn-3:HUL.InstRepos:3201599

\section{Terms of Use}

This article was downloaded from Harvard University's DASH repository, and is made available under the terms and conditions applicable to Other Posted Material, as set forth at http:// nrs.harvard.edu/urn-3:HUL.InstRepos:dash.current.terms-of-use\#LAA

\section{Share Your Story}

The Harvard community has made this article openly available.

Please share how this access benefits you. Submit a story.

\section{Accessibility}




\title{
Measuring Expressed Emotion: An Evaluation of the Shortcuts
}

\author{
Jill M. Hooley and Holly A. Parker \\ Harvard University
}

\begin{abstract}
The construct of expressed emotion (EE) is a highly reliable and valid predictor of poor clinical outcomes in patients with major psychopathology. Patients are at early risk for relapse if they live with family members who are classified as high in EE. Conventionally, EE is assessed with the Camberwell Family Interview (CFI), a semistructured interview that is conducted with the patient's key relatives. Unfortunately, training in the CFI is difficult to obtain. The CFI is also time-consuming to administer and labor intensive to rate. In this article, the authors discuss alternative ways of assessing EE. They also evaluate the predictive validity of these measures and make recommendations for researchers and clinicians interested in using these assessments.
\end{abstract}

Keywords: expressed emotion, assessment, rating scales, Five Minute Speech Sample (FMSS), perceived criticism

The construct of expressed emotion (EE) is now well established as an important measure of the family environment. Developed in the 1960s and 1970s in England by Brown, Birley, and Wing (1972; Brown \& Rutter, 1966), EE reflects the extent to which the close family members of an identified patient express critical, hostile, or emotionally overinvolved attitudes toward the patient during a private interview with a researcher. Several decades of research have established EE as a highly reliable psychosocial predictor of psychiatric relapse. When patients live in a family environment that is characterized by critical, hostile, or emotionally overinvolved or intrusive attitudes (i.e., in high-EE families), they are at significantly elevated risk of early relapse compared with patients who do not live in such a family environment. The association between high levels of EE and symptom relapse has been well demonstrated for disorders such as schizophrenia and depression (Butzlaff \& Hooley, 1998; Leff \& Vaughn, 1985). The predictive validity of EE has also been found for a broad range of other psychopathological conditions, including anxiety disorders (Chambless, Bryan, Aiken, Steketee, \& Hooley, 2001), substance abuse (O'Farrell, Hooley, Fals-Stewart, \& Cutter, 1998), and eating disorders (see Butzlaff \& Hooley, 1998).

Although ratings of EE are often considered to be characteristic of relatives, EE is most appropriately regarded as a measure of the patient-relative relationship. Examination of interaction patterns reveals that high levels of EE are associated with reciprocal negativity within the relationship (Cook, Kenny, \& Goldstein, 1991; Hahlweg et al., 1989; Hooley, 1990; Simoneau, Miklowitz, \& Saleem, 1998).

Jill M. Hooley and Holly A. Parker, Department of Psychology, Harvard University.

Correspondence concerning this article should be addressed to Jill M. Hooley, Department of Psychology, Harvard University, 33 Kirkland Street, Cambridge, MA 02138. E-mail: jmh@wjh.harvard.edu
Current models conceptualize EE within an interactional framework, with characteristics of patients (e.g., uncooperativeness, negativity) engendering critical attitudes in relatives who are less flexible and tolerant and more inclined toward controlling behaviors to begin with (see Hooley \& Gotlib, 2000).

$\mathrm{EE}$ is of interest to researchers and clinicians because it predicts symptom relapse in patients and because familybased interventions that seek to reduce EE have had success in decreasing patients' relapse rates (Hogarty et al., 1986; Leff, Kuipers, Berkowitz, Eberlein-Fries, \& Sturgeon, 1982). However, difficulties with measurement limit the practical utility of the construct. In response to this, researchers have developed several shorter methods for measuring EE. In this article, we describe the conventionally accepted method of assessing EE and discuss some of the drawbacks associated with this approach. We then consider a number of measures derived from the $\mathrm{EE}$ construct that have been designed to be used as alternatives. At the conclusion of the article, we provide specific recommendations to those interested in measuring EE in their research or clinical practices.

Our review is restricted to measures that, at minimum, have been validated against the Camberwell Family Interview (CFI; Leff \& Vaughn, 1985), because this is the conventional method used to assess EE. We are aware, however, that such an approach has its limitations. Developing alternative measures of EE (as opposed to better predictors of relapse) may reflect a reification of the EE construct that is neither warranted nor appropriate (see Hooley \& Richters, 1991). Nonetheless, the issue of whether there is a quicker way of assessing EE is often raised. In recognition of this, we restrict our discussion to alternative forms of assessment that (a) are conceptually based on the EE construct, (b) have been validated against the CFI, and (c) have predictive validity data available. These criteria mean that we exclude measures such as the 
Influential Relationships Questionnaire (Baker, Helmes, \& Kazarian, 1984), which is not based on the EE construct; the Patient Rejection Scale (Kreisman, Simmens, \& Joy, 1979), which has not been validated against the CFI; and the Adjective Checklist (Friedmann \& Goldstein, 1993), which lacks data on its predictive validity. These assessment instruments are reviewed in Van Humbeeck, Van Audenhove, De Hert, Pieters, and Storms (2002).

\section{The CFI}

The gold-standard measure of EE is a semistructured interview known as the CFI (Leff \& Vaughn, 1985). The CFI is conducted with the patient's key relative or relatives (typically parents or a spouse) without the patient being present. Parents are interviewed separately, and the interview is always recorded for later coding.

When it is administered well, the CFI is more like a conversation with the relative than a formal interview. Questions address the onset of the patient's disorder and the symptoms that were apparent to the relative in the months prior to the patient's hospitalization or exacerbation of illness. Also discussed are the level of tension in the household, irritability, participation of the patient in routine household tasks, and the daily routines of the patient and various family members. The typical length of the interview is between 1 and $2 \mathrm{hr}$.

The CFI is used to make ratings on five scales. These are Criticism, Hostility, Emotional Overinvolvement (EOI), Warmth, and Positive Remarks. Although ratings on five scales are made, practically speaking, the most important EE scales are Criticism, Hostility, and EOI. It is on the basis of the ratings on these scales that the classification of family members as high or low in EE is made. For example, if a relative makes an above-threshold number of critical remarks (six or more in the case of schizophrenia), makes any remark that is rated as hostile, or shows evidence of marked overinvolvement (a rating of 3 or more on a $0-5$ scale), he or she is classified as high in EE.

It is clear from the empirical literature that EE, measured with the CFI, is a construct with considerable concurrent and predictive validity. Relatives who are classified as high in EE behave in more negative ways when they interact with the patient than do low-EE relatives (Hooley, 1986; Miklowitz, Goldstein, Falloon, \& Doane, 1984). CFI-rated EE is also highly predictive of symptom relapse in patients with a wide variety of disorders (e.g., Butzlaff \& Hooley, 1998; Chambless \& Steketee, 1999; O'Farrell et al., 1998), and the predictive validity of the construct has been demonstrated cross-culturally (e.g., Phillips \& Xiong, 1995; Tanaka, Mino, \& Inoue, 1995). However, several problems limit the practical utility of EE. First, EE can only be assessed by raters who have received between 40 and $80 \mathrm{hr}$ of formal training. Second, training in rating EE is both expensive and difficult to obtain. Finally, each CFI takes $1-2 \mathrm{hr}$ to administer and another $2-3 \mathrm{hr}$ to code. These factors combine to make the assessment of EE both costly and cumbersome.

Although it might be natural to think that clinicians who are familiar with the EE construct might be able to make EE assessments in the absence of formal training, empirical research suggests that this is not the case. When psychiatrists who were aware of the construct were asked to rate the EE status of their patients' relatives (for whom formal EE ratings had been obtained with the CFI), they performed no better than chance (King, Lesage, \& Lalonde, 1994). In light of this, it is not surprising that there has been a great deal of interest in developing shorter, alternative measures of EE.

In some cases, researchers have simply looked to reduce the time taken to administer the CFI by removing some of its sections (Mueser, Bellack, \& Wade, 1992). However, although this shortens the CFI to about 45 min, coding the interview still takes a considerable amount of time. As a result, the abbreviated CFI has not been embraced by clinicians and researchers. Other investigators have taken different approaches, however, and have created questionnaires or developed methods that have been more successful in increasing the accessibility of the construct. In the following sections, we discuss some of the most promising alternatives.

\section{The Five Minute Speech Sample (FMSS)}

The FMSS (Magaña et al., 1986) requires the family members to talk about their thoughts and feelings about the patient for 5 uninterrupted minutes. The speech is recorded and later coded for the overall level of EE, criticism, and EOI. There is no hostility rating on the FMSS. Warmth is not assessed either, although the FMSS does provide a frequency count of the number of positive comments relatives make about the patient. This is used in the FMSS EOI rating.

The FMSS is similar to the CFI in that family members talk about the patient and their relationship. The FMSS, however, requires less time to administer (5 $\mathrm{min}$ ) and score (20 min) compared with the CFI. One or more critical comments, negative comments about the relationship, or a critical statement at the start of the interview are all indicative of high criticism on FMSS, whereas FMSS EOI is characterized by extreme praising or loving comments about the patient, crying, or excessive emotional involvement and self-sacrifice.

In Magaña et al.'s. (1986) original study, the FMSS was validated against the CFI. Supporting the concurrent validity of the FMSS, 15 of 23 relatives who were rated as high $\mathrm{EE}$ on the CFI were also rated as high EE on the FMSS. This corresponds to a sensitivity (percentage of high-EE relatives correctly identified) of $65.2 \%$. Of the 17 relatives who were rated as low EE on the CFI, 15 were correctly identified by the FMSS. The specificity (number of low-EE relatives correctly identified) of the FMSS was therefore $88.2 \%$. Magaña et al. (1986) obtained virtually identical results when they compared the CFI and FMSS in a Spanish-speaking sample. The number of high-EE relatives correctly identified by the FMSS was 15 of 30 (sensitivity = $50.0 \%)$. For low-EE relatives, the specificity of the FMSS was 40 out of 44 , or $90.9 \%$. Somewhat more impressive results for sensitivity (sensitivity $=80.0 \%$; specificity $=$ 
71.0\%) were reported in a German sample (Leeb et al., 1991).

There was significant overall agreement between the CFI and the FMSS ratings in both of the samples reported in Magaña et al. (1986) and in the data from Leeb et al. (1991). In the former study, the overall agreement was $75.0 \%$; in the latter, it was $73.0 \%$. Moreover, examination of the data reveals that participants who are rated as high EE on the FMSS are almost always classified as high EE when the CFI is used. However, approximately $20.0 \%$ of the participants who are classified as low EE on the FMSS are actually classified as high EE if the CFI is administered. In other words, high-EE relatives tend to be underidentified by the FMSS.

Other investigators have also noted this problem. Malla, Kazarian, Barnes, and Cole (1991) failed to find a significant association between CFI and FMSS ratings and reported that the FMSS correctly identified $59.0 \%$ of the CFI high-EE participants and $84.0 \%$ of the CFI low-EE participants in their study. Similarly, Fujita et al. (2002) reported that, of 13 high-EE relatives of schizophrenia patients in Japan who were identified by the CFI, only 4 were identified as high EE by the FMSS. In contrast, 37 out of 44 low-EE relatives were correctly identified by the FMSS. These figures translate into a sensitivity of $30.8 \%$ and a specificity of $84.1 \%$ and again suggest that a major problem with the FMSS is the tendency to underidentify high-EE family members.

The coding instructions for the FMSS specifically instruct raters to be conservative and to stay away from ratings that would lead to a high-EE assessment if they are in doubt. However, the validity of the FMSS increases when relatives who are borderline are classified as high EE. In the relatives of Japanese inpatients with mood disorders, sensitivity increased from $66.7 \%$ to $100.0 \%$ when relatives who scored at the borderline of low EE were assigned to the high-EE group (Shimodera et al., 2002). These researchers also reported that the sensitivity of the FMSS in a sample of Japanese relatives of schizophrenia patients increased from $53.8 \%$ to $92.3 \%$ when borderline participants were included in the high-EE group (Shimodera et al., 1999), although making these changes resulted in a decrease in specificity from $65.2 \%$ to $52.2 \%$.

The highest association between FMSS ratings and CFI ratings comes from a study by Moore and Kuipers (1999). The authors used the FMSS to assess EE in professional caregivers of hospitalized psychiatric patients. Moore and Kuipers reported an $89.7 \%$ agreement in EE classification between the FMSS and the CFI. Moreover, the number of critical comments made during the CFI was highly correlated with the number of criticisms rated in the FMSS ( $r=$ $.74)$ and with relationship quality as assessed in the FMSS $(r=-.71)$. However, as the authors noted, readers need to take care with the interpretation of these findings because the same researcher rated both the FMSS and the CFI. This might have led to higher concordance between the CFI and FMSS ratings than might otherwise have been the case.

The FMSS is one of the most widely used alternative measures of EE. It is highly favored by researchers working with children and has been found to be correlated with mother-child attachment security (Jacobsen, Hibbs, \& Ziegenhain, 2000), maternal behavior (Daley, SonugaBarke, \& Thompson, 2003), and child and adolescent behavior problems (Hirshfeld, Biederman, Brody, Faraone, \& Rosenbaum, 1997; Peris \& Baker, 2000; Wamboldt, O'Connor, Wamboldt, Gavin, \& Klinnert, 2000). Research on the quality of interactions between parents of asthmatic children and their children's physicians further suggests that the FMSS identifies negative parent-physician relationships (Cohen \& Wamboldt, 2000).

As might be expected from a measure that has only modest association with the CFI, however, the evidence for the predictive validity of the FMSS tends to be mixed. For example, Thompson et al. (1995) reported that the FMSS did not predict exacerbation of psychotic symptoms in 33 male patients with schizophrenia over a 1-year follow-up. Similar negative findings between FMSS-rated EE and relapse in psychotic patients have also been reported (Jarbin, Grawe, \& Hansson, 2000; Kurihara, Kato, Tsukahara, Takano, \& Reverger, 2000; Nugter, 1997; Tattan \& Tarrier, 2000; Uehara et al., 1997). However, when Uehara et al. (1997) assigned relatives who were borderline in their ratings to the high-EE group, they did find a significant association between the FMSS and relapse in outpatients with schizophrenia.

Findings such as these likely reflect the fact that the FMSS provides a less reliable estimate of EE than the CFI does. This suggests that if the FMSS were administered on more than one occasion, the aggregated EE assessment might be a better predictor of clinical outcome than either of the single assessments. Consistent with this, Jarbin et al. (2000) found that neither EE assessed at hospital admission nor EE assessed at hospital discharge predicted 1- and 2 -year relapse rates in adolescents with psychotic disorders. However, when they combined the results of the two FMSS assessments (and especially if they included borderline ratings as high EE), the aggregated classification of EE did significantly predict patients' 2 -year relapse rates.

For schizophrenia, the clearest support for the predictive validity of the FMSS comes from a large Israeli study of 93 schizophrenia patients and 15 schizoaffective inpatients (Marom, Munitz, Jones, Weizman, \& Hermesh, 2002, 2005). The authors assessed relatives' EE using the FMSS and initially followed patients for 9 months after discharge from the hospital. Patients with high-EE relatives were significantly more likely to be readmitted to the hospital than patients who had low-EE relatives (odds ratio [OR] = 2.6). A subsequent investigation involving the same patients further demonstrated that FMSS-assessed EE was associated with the course of schizophrenia over a much longer (7-year) follow-up period (Marom et al., 2005). Although using hospital readmission as a measure of clinical outcome has its problems in EE studies (high-EE relatives may seek hospitalization for their patient relative more readily than do low-EE relatives), the data of Marom et al. suggest that the FMSS does have some predictive validity for patients with schizophrenia and schizophrenia-related conditions.

CFI-assessed EE is a highly reliable predictor of relapse 
in patients with mood disorders (Butzlaff \& Hooley, 1998). It is therefore encouraging to note that $\mathrm{EE}$, assessed with the FMSS, has been linked to worse clinical outcomes in depressive disorders. In what was the first ever demonstration of the predictive validity of FMSS-assessed EE, Asarnow, Goldstein, Tompson, and Guthrie (1993) reported that children with mood disorders were significantly more likely to recover if their mother was rated as low in EE. In this study, none of the 11 children who lived with a high-EE mother had recovered by the time of the 1-year follow-up. In contrast, $53.0 \%$ ( 8 of 15) of the children who lived with a low-EE mother recovered. Subsequent research has demonstrated that the FMSS also predicted 6-month clinical outcomes in 40 depressed outpatients in Japan (Uehara, Yokoyama, Goto, \& Ihda, 1996).

Finally, researchers have also found partial evidence for the predictive validity of the FMSS in patients with bipolar disorder. Forty-seven patients with Bipolar I disorder and their family members participated in a longitudinal study on the relation between EE and outcome 1 year later. When initial symptom severity was controlled and participants were divided into high- versus low-EE groups, with borderline EE relatives excluded, the FMSS did not significantly predict relapse of any type (depressed or manic). When initial symptom severity was controlled and borderline EE relatives were included in the high-EE group, however, high $\mathrm{EE}$ on the FMSS predicted relapse of depression (OR = $5.40)$ but not relapse of mania $(\mathrm{OR}=1.30)$ or relapse overall $(\mathrm{OR}=2.13)$. Thus, although the FMSS did not predict relapse for mania, it did predict the recurrence of depressive symptoms (Yan, Hammen, Cohen, Daley, \& Henry, 2004).

In summary, the FMSS has advantages and disadvantages as a measure of EE. On the positive side, the measure is shorter than the CFI and takes less time to code. It can be used in cases in which the respondent does not know the patient especially well and would not be able to answer all the questions contained in the CFI (e.g., treatment team members). It also has demonstrated predictive validity with respect to depression and, to a lesser degree, schizophrenia. However, as an alternative measure of EE, the FMSS leaves much to be desired. Although the measure takes less time to administer, it requires the participation of the relative, and trained coders must still be used. The FMSS also tends to underidentify high-EE relatives. This problem with reliability may explain the mixed findings with regard to its predictive validity. For disorders for which the effect size of the EE-relapse relation is higher (e.g., depression; see Butzlaff \& Hooley, 1998), the FMSS may still provide a good enough estimate to lead to significant findings. For disorders that show a lower size of association between EE and relapse, however (e.g., schizophrenia; see Butzlaff \& Hooley, 1998), larger sample sizes, such as were found in the study of Marom et al. (2002), may be required to compensate for the poorer reliability of the measure and obtain significant findings. Most important, when researchers fail to find an association between FMSS-rated EE and any given outcome, the chance that such a negative finding represents a Type II error is much more of a concern than it would have been if the researchers had used the CFI. On a more optimistic note, when researchers report a significant association between FMSS-rated EE and a given outcome, the chances that they might have noted a similar finding if they had used the CFI to assess EE are probably quite high.

\section{Level of Expressed Emotion Scale (LEE)}

The LEE (Cole \& Kazarian, 1988) is a 60-item, selfreport measure that assesses the emotional environment in the patient's most important relationships. Items in the LEE Scale are based on the EE construct, and the four subscales are Intrusiveness, Emotional Response, Attitude Toward Illness, and Tolerance and Expectations. Items are rated in a true-false format, and the scale generates a score for the level of EE overall as well as a score for each of the four response patterns. Two versions of the LEE Scale are available. The Patient Version asks patients to evaluate their relationship with their closest relative (i.e., the relative with whom they live). The Relative Version requires the close relative to evaluate his or her relationship with the patient. Because the LEE Scale is a self-report measure, it is easier to administer and requires less time to score than the CFI.

The initial report on the LEE demonstrated high internal consistency for both the total scale and the subscales as well as high test-retest reliability among patients with schizophrenia (Cole \& Kazarian, 1988). However, the correlation between the total score on the LEE Relative Version and the number of critical comments relatives made during the CFI was only .38 (Kazarian, Malla, Cole, \& Baker, 1990). For the Patient Version of the LEE, total LEE score was correlated .32 with the number of critical comments relatives made during the CFI.

Despite its modest association with the CFI, Cole and Kazarian (1993) reported that the Patient Version of the LEE was a good predictor of relapse among patients with schizophrenia (relatives' LEE scores were not obtained in this study). That is, patients who were readmitted to the hospital 2 and 5 years after the initial assessment of their symptoms had higher LEE scores on initial assessment than did nonreadmitted patients. Moreover, when the investigators divided patients into high- and low-LEE scorers using a median split $(M d n=9)$, individuals who scored high on the LEE at the initial assessment were significantly more likely to be rehospitalized 1,2 , and 5 years later (Cole \& Kazarian, 1993). High scorers on the LEE were also three times more likely to be hospitalized during the 5-year follow-up period than were patients who scored low on the scale. Using a more heterogeneous clinical sample, Donat, Geczy, Helmrich, and LeMay (1992) also reported that the total LEE score predicted rehospitalization in patients with a variety of psychiatric disorders.

Thorough evaluation of the LEE scale is complicated by the fact that not all investigators use the LEE in its standard (60-item) form. Gerlsma, van der Lubbe, and van Nieuwenhuizen (1992) translated the scale into Dutch, replaced the true-false format with a 4-point Likert scale response format, and conducted a principal-component analysis on the original 60 items. This revealed three factors, which were 
labeled Lack of Emotional Support $(\alpha=.89)$, Intrusiveness/ Control $(\alpha=.78)$, and Irritability $(\alpha=.79)$. The Cronbach's alpha coefficient for the resulting 33-item scale was .91. This is quite high and may be indicative of a secondorder factor in addition to the three subscales. Although the scale has adequate internal validity, the authors provided no information about how well it correlated with the CFI.

The predictive validity of this factorially derived 33 -item version of the LEE was later examined with depressed patients and their partners (Gerlsma \& Hale, 1997). Again, however, the evaluation of the LEE is complicated by a further modification to the scale. In this case, the researchers added another subscale designed to assess perceived criticism (PC; described in more detail later), as formulated by Hooley and Teasdale (1989). Thus, the LEE in this study is not the same LEE as described by Cole and Kazarian (1988). Nor is it exactly the same as the version of the LEE reported in Gerlsma et al. (1992), at least with regard to total LEE scores (because these contain the added Criticism scale). However, the data from the three subscales are comparable.

With this in mind, we note that Gerlsma and Hale (1997) reported that although the LEE subscales of Emotional Support and Intrusiveness did not significantly predict how well patients fared, depressed patients who reported higher levels of irritability in their partner did less well in the following 6 months $(r=-.46)$. The best predictor of clinical outcome, however, was the newly added Criticism scale. The more critical patients rated their partner as being, the less change they showed in their scores on the Beck Depression Inventory $(r=-.53$; Beck, Ward, Mendelson, Mock, \& Erbaugh, 1961) and on the Symptom Checklist 90 (Derogatis, Lipman, \& Covi, 1973; $r=-.64$ ) over the 6-month follow-up. With regard to concurrent validity, there is also evidence from a sample of patients with schizophrenia that the Criticism subscale of the LEE has a higher correlation with criticism assessed with the CFI $(r=.44)$ than either the total LEE Scale $(r=.36)$ or the Emotional Support, Intrusiveness, or Irritation subscales (Van Humbeeck, Van Audenhove, \& Declercq, 2004).

Finally, we note that researchers have also examined the predictive validity of the LEE with regard to eating disorders. Moulds et al. (2000) administered the 38-item version of the LEE (this is the 33 item-version with the added Criticism subscale) to women with anorexia nervosa who had just left the hospital. Participants completed the LEE for their siblings, mother, and father and were assessed 6 weeks later for change in weight and improvement in psychological functioning, as measured by the Eating Disorder Inventory-2 (EDI-2; Garner, 1991). LEE total scores for siblings, mothers, and fathers did not predict weight gain. A single family index of the LEE (i.e., a combined LEE score for siblings and parents) did not predict change in body weight either. For two subscales of the EDI-2 (Bulimia and Maturity Fears), higher composite LEE scores were associated with patients showing more improvement over a 6-week period; for two other scales of the EDI-2 (Interpersonal Distrust and Perfectionism), higher composite LEE scores were associated with patients showing less improvement over this time period (Moulds et al., 2000).

Data from the LEE are difficult to evaluate because of the changes in the instrument that have occurred over time. What began as a 60 -item questionnaire is now a 38 -item questionnaire that is more often administered to patients than to the relatives. Correlations with the CFI, when available, appear to be quite modest. We also note that, in Cole and Kazarian's (1993) study on the predictive validity of the measure, patients' scores on the 60-item version of the LEE did not predict 1-year rehospitalization rates, although they did predict rehospitalization rates over 2 and 5 years. Although the 60-item version may be a possible alternative for the CFI, at least with respect to patients with psychotic disorders, much more research needs to be conducted to establish the validity of this measure for other disorders. The version of the LEE derived from Gerlsma et al.'s (1992) factor analysis may represent a positive step psychometrically. However, until there is more evidence showing that the revised LEE predicts the kinds of negative psychiatric outcomes predicted by the CFI, it cannot be considered to be a viable alternative measure of EE.

\section{Family Attitude Scale (FAS)}

The FAS (Kavanagh et al., 1997) is a 30-item self-report measure of EE. It is similar to the LEE in that either relatives or patients may complete it. Examples of items include "I wish he were not here," "He appreciates what I do for him," "I lose my temper with him," "He ignores my advice," and "I feel very close to him."

Kavanagh et al. (1997) reported that the FAS had very high internal consistency among a sample of students' parents as well as with both female and male students. It also exhibited sound concurrent validity. For instance, fathers' and mothers' FAS scores were associated with expression of anger, trait and state anger, trait and state anxiety, argument frequency, seriousness of worst argument, and duration of argument. Moreover, in a sample of patients with schizophrenia and schizoaffective disorder and their relatives, the FAS showed high internal consistency for mothers $(\alpha=.95)$, fathers $(\alpha=.94)$, and other relatives $(\alpha=.96)$.

Most important, the FAS has validity with respect to the CFI. Kavanagh et al. (1997) reported that mothers' and fathers' total FAS scores were correlated with criticism as measured by the CFI ( $r=.38$ for fathers; $r=.66$ for mothers). Total FAS scores also correlated with hostility ratings made from the CFI $(r=.31$ for fathers; $r=.39$ for mothers). Although FAS scores were not associated with CFI-assessed EOI ( $r=.05$ for fathers; $r=.10$ for mothers), there was an association between the FAS and CFI warmth ( $r=-.36$ for fathers; $r=-.42$ for mothers).

In a subsequent study, Fujita et al. (2002) administered the FAS to the families of schizophrenia patients in Japan. Echoing the earlier findings of Kavanagh et al. (1997), FAS scores were significantly associated with criticism $(r=.47)$, hostility $(r=.37)$, and warmth $(r=-.39)$ as assessed with the CFI. Finally, Pourmand (2005) reported that FAS scores were higher in high-EE families than they were in low-EE 
families. With a cutoff score of 55 on the FAS, $65.0 \%$ (22 of 34) of high-EE cases and $75.0 \%$ (15 of 20) of low-EE cases were correctly identified. Correlations between the FAS and CFI-assessed critical comments were .29 for fathers and .27 for mothers. Although these correlations did not attain statistical significance, there was a significant association between FAS scores and hostility ( $r=.34$ for fathers; $r=.38$ for mothers). Mothers' FAS scores were also significantly correlated with EOI $(r=.31)$, although this was not true for fathers $(r=.06)$.

Overall, the early findings with the FAS are encouraging. The measure has significant overlap with the CFI. In a small sample of patients with anorexia nervosa and their siblings, Moulds et al. (2000) also found that siblings' scores on the FAS were correlated .53 with patients' scores on the 38-item LEE. It is important to note that data on the predictive validity of the FAS are now becoming available. In a sample of 62 patients diagnosed with psychosis and comorbid substance abuse, Kavanagh and Pourmand (2005) reported that baseline family FAS scores were higher in patients who subsequently relapsed. However, the strongest predictor of patient relapse was EE, assessed with the CFI.

\section{Perceived Criticism (PC)}

Of all the alternative measures of EE, the most simple is the PC measure. Recognizing that the most important element of EE was criticism, Hooley and Teasdale simply asked patients to rate how critical they thought their relative was of them using a 10-point Likert-type scale. In addition, they asked patients how critical they thought they were of their relative using the same scale. A subsequent addition expanded the questions to include ratings of upset ("When [your relative] criticizes you, how upset do you get" or "When you criticize [your relative] how upset does he or she get?"). In all cases, these items can also be completed by the relatives themselves.

Hooley and Teasdale (1989) assessed PC in a sample of depressed patients and their spouses. Patients' PC scores were correlated .51 with spouses' overall EE ratings (high or low) as assessed with the CFI, although the correlation with spouses' criticism assessed with the CFI was a more modest .27. Nonetheless, patients' perceptions of their partner's criticism level (assessed during the index hospitalization) was highly predictive $(r=.64)$ of patient relapse over the course of a 9-month follow-up. Patients who relapsed rated their spouse as significantly more critical than did patients who remained well. Of interest, none of the patients who gave their spouse a PC score less than 2 relapsed during the follow-up period. In contrast, all of the patients who assigned their spouse a PC rating of 6 or higher relapsed.

It is unlikely that illness severity explains the relation between patients' PC ratings and subsequent relapse, because depressed patients' PC scores were not related to their Beck Depression Inventory scores $(r=.02)$ or to clinical symptomatology $(r=-.16)$. Both patient and spouse PC ratings showed also good test-retest reliability from initial assessment to 3 months later $(r=.75$ for patients; $r=.60$ for spouses; Hooley \& Teasdale, 1989). Chambless et al. (2001) also demonstrated that PC scores were not related to overall patient functioning $(r=-.18)$ or overall psychopathology $(r=.12)$ in a sample of patients diagnosed with anxiety disorders. Similar findings showing a lack of association between PC ratings and depression, global functioning, neuroticism, and personality disorder symptoms have also been reported (Riso, Klein, Ouimette, Anderson, \& Lizardi, 1996).

It is interesting to note that patients' ratings of PC may provide a more valid assessment of the EE level of the person being rated than self-report ratings obtained directly. In Hooley and Teasdale's (1989) study, spouses' ratings of how critical they thought they were of the patient were correlated .00 with the number of critical comments the spouse actually made during the CFI. In another study, in which patients with schizophrenia were asked to rate their therapists, therapists' self-report ratings of how critical they were only correlated .21 with how critical they were on the CFI. However, patients ratings of therapists' criticism were significantly correlated $(r=.45)$ with therapists' criticism rated on the CFI (Van Humbeeck et al., 2004). Patients' PC ratings also correlated .47 with their total score on the 38 -item LEE Scale. However, most of this association between PC and the LEE comes from the correlation between PC and the Criticism subscale of the LEE $(r=.45)$.

In addition to the demonstrated predictive validity of PC for unipolar depression, the PC measure has shown good predictive validity for other disorders. Chambless and Steketee (1999) reported that PC ratings predicted changes in symptom severity from pretest to posttest for patients with obsessive-compulsive disorder or panic disorder with agoraphobia $(r=.36)$. This association was not explained by other clinical variables (Renshaw, Chambless, \& Steketee, 2001). PC was also associated with anxiety symptoms after behavioral treatment for obsessive-compulsive disorder and panic (Renshaw, Chambless, \& Steketee, 2003). Moreover, in a sample of 106 men diagnosed with substance abuse problems, patients' $\mathrm{PC}$ ratings were significantly predictive of worse clinical outcomes in the 1-year posttreatment period. That is, men who rated their wives as higher in criticism had significantly fewer days when they were abstinent $(r=-.33)$ and were significantly more likely to relapse $(r=.39)$. They also relapsed more quickly. The association between PC and outcome also remained after patient background variables were statistically controlled (Fals-Stewart, O'Farrell, \& Hooley, 2001).

For bipolar illness, however, the research findings look a little different. In a study of 360 bipolar patients, Miklowitz, Wisniewski, Miyahara, Otto, and Sachs (2005) reported that patients' symptomatic outcomes were not predicted by the amount of criticism patients reported receiving from their relatives. Instead, patients who reported feeling most upset when they were criticized by family members had more severe depressive and manic symptoms at 1-year follow-up. They also had a lower percentage of days well during the follow-up pe- 
riod. These are interesting findings. However, we note that how upset a patient reports feeling in response to being criticized is not the same conceptually as the patient's rating of the severity of the relative's criticism.

Although ratings of PC have demonstrated concurrent and predictive validity, the practical utility of this measure may be limited by cultural factors. When Okasha et al. (1994) tried to use the PC measure in a sample of unipolar and bipolar depressed patients in Egypt, they noted that the use of a 10-point scale to detect opinions was not familiar in Egyptian culture. They also noted that some patients did not want to evaluate their caregivers with "mere numbers" and some expressed concern about the "real motive or meaning" behind the question (p. 1002). The researchers tried to simplify the scale by reducing it to three categories of criticism (low, moderate, or high). However, they found no association between this modified scale and relapse.

In summary, $\mathrm{PC}$ ratings are not a substitute for the CFI. However, they can be obtained from patients extremely quickly. PC ratings also appear to be relatively independent of current levels of psychopathology and tend to be rather stable across time. They also correlate reasonably well with EE as assessed by the CFI, although correlations with the Criticism subscale of the CFI can sometimes be much more modest. Despite this, PC ratings have been shown to predict poor clinical outcomes in depressed patients, patients with anxiety disorders, and patients with substance abuse problems. Unfortunately, there are no data concerning the predictive validity of PC for patients with schizophrenia. Moreover, for patients with bipolar disorder, how upset patients report being when they are exposed to criticism may have more predictive validity than PC ratings themselves.

\section{Summary and Recommendations}

A major conceptual problem that is unresolved is what $\mathrm{EE}$ and the various alternative assessments of EE actually measure. For example, how much does a high EE rating tell the researcher about the relative, and how much does it tell about the patient or the family system more broadly (see Cook \& Kenny, 2004)? Do alternative measures of EE index approximately the same thing? Studies that have explored the associations between CFI-rated EE and LEE, PC, or FAS scores show that the measures often are not highly correlated. This raises questions about whether the measures tap the same underlying construct but with high measurement error or whether they tap different aspects of individual or family functioning entirely.

Although we lack a full understanding of the EE construct and need to learn more about what is being captured in the various alternative measures, there is an obvious clinical need to identify relapse-prone patients. Given this, some recommendations about the use of the alternative measures of EE (summarized in Table 1) are warranted.

The CFI has many advantages as a measure of EE. It is widely used. Moreover, studies that use this form of $\mathrm{EE}$ assessment provide data that can readily be incorporated into the large body of EE research that has been conducted over the last 40 years. The CFI is also the only form of EE assessment that provides data on all five EE variables (criticism, hostility, EOI, warmth, and positive remarks). Given the growing interest in measuring family warmth as a possible moderating variable (e.g., Lopez et al., 2004), the comprehensive coverage of family emotions provided by the CFI is a clear asset.

Another major advantage of the CFI is that, when it is conducted by a skilled clinical researcher, it can be a remarkably positive experience for the relative being interviewed. During the CFI, the relative is given an opportunity to tell his or her story about what it has been like to be with the patient and deal with mental illness in the family. It is not unusual for family members to express gratitude to the interviewer for listening to what they have to say and taking their perspective seriously. In longitudinal research, when the research team and the family remain in contact during an extended period of data collection, the advantages of this kind of positive connection cannot be underestimated.

Another major advantage of the CFI is that it provides a great deal of information beyond that needed to make EE ratings. It provides information about the patient's symptomatology. It also provides a spontaneous sample of the relative's speech that can be used for other research purposes, such as coding attributions (see Barrowclough, Johnston, \& Tarrier, 1994; Hooley \& Licht, 1997) or controlling behaviors (Hooley \& Campbell, 2002). The CFI may also be flexible enough in its probes to allow it to be successfully modified for use in crosscultural research. In short, we believe that the CFI provides an extremely good return on the time investment that it demands.

As we have noted, however, the CFI is labor intensive and requires a great deal of specialized training. A shorter alternative to the CFI is to use the FMSS. Although training is still required to code the FMSS, the coding time is considerably reduced. One problem with the FMSS, however, is that it underidentifies high-EE relatives. What this means in practical terms is that if a relative is identified as high EE with the FMSS, the probability that the CFI would also identify that relative as high EE is quite high. Just under one third of relatives rated as low EE on the FMSS, however, may not be low EE on the basis of the CFI. This unreliability may explain why the predictive validity of the FMSS is rather uneven. For these reasons, we are unable to fully endorse the FMSS as an alternative measure of EE. In a review of the literature, Van Humbeeck et al. (2002) reached a similar conclusion.

The FMSS is perhaps best suited for use in situations in which clinical researchers wish to identify high-EE relatives, perhaps as a target for family-based interventions. They can save time by screening relatives with the FMSS and then using the CFI to provide a more thorough assessment of those who are rated as low in EE. The FMSS is also a good substitute for the CFI in cases in which the latter might not be feasible for other reasons. For example, an informant (e.g., health care worker) may not know the patient well enough to answer all the questions contained in 
Table 1

Summary of Alternative Expressive Emotion (EE) Measures

\begin{tabular}{|c|c|c|c|c|}
\hline Measure & $\begin{array}{l}\text { Administration } \\
\text { time }\end{array}$ & Format & Concurrent validity (CFI) & Predictive validity \\
\hline \multirow[t]{3}{*}{ FMSS } & $25 \mathrm{~min}$ & $\begin{array}{l}\text { Speech sample from } \\
\text { relative; coded by } \\
\text { trained coders }\end{array}$ & $\begin{array}{l}\text { FMSS Criticism and overall } \\
\text { EE, } r=.44\end{array}$ & $\begin{array}{l}\text { Mixed predictive validity for } \\
\text { schizophrenia (Jarbin et al., } \\
\text { 2000; Maron et al., 2002; } \\
\text { Thompson et al., 1995) }\end{array}$ \\
\hline & & & $\begin{array}{l}\text { FMSS EOI and overall EE, } \\
r=.38 \text { (Magaña et al., 1986) }\end{array}$ & $\begin{array}{l}\text { Predicts recovery in depressed } \\
\text { children (Asarnow et al., 1993) }\end{array}$ \\
\hline & & & & $\begin{array}{l}\text { Predicts relapse of depression but } \\
\text { not mania in bipolar patients } \\
\text { (Yan et al., 2004) }\end{array}$ \\
\hline LEE & $10-15 \min$ & $\begin{array}{l}60 \text {-item questionnaire } \\
\text { completed by patients } \\
\text { or relatives }\end{array}$ & $\begin{array}{l}\text { LEE and CFI Criticism, } \\
r=.38 \text { for relatives' } \\
\text { version; } r=.32 \text { for } \\
\text { patients' version } \\
\text { (Kazarian et al., 1990) }\end{array}$ & $\begin{array}{l}\text { Predicts rehospitalization at } 2 \text { and } \\
5 \text { years for schizophrenia (Cole } \\
\text { \& Kazarian, 1993) } \\
\text { Predicts rehospitalization in mixed } \\
\text { patient sample (Donat, 1996) }\end{array}$ \\
\hline FAS & $5-10 \mathrm{~min}$ & $\begin{array}{l}\text { 30-item questionnaire } \\
\text { completed by relatives }\end{array}$ & $\begin{array}{l}\text { FAS and overall EE, } r=.38 \\
\text { (calculated from Pourmand, } \\
\text { 2005) }\end{array}$ & $\begin{array}{l}\text { Predicts relapse in patients with } \\
\text { psychotic disorders (Kavanagh } \\
\& \text { Pourmand, 2005) }\end{array}$ \\
\hline \multirow[t]{4}{*}{$\mathrm{PC}$} & $1 \mathrm{~min}$ & $\begin{array}{l}\text { One question completed } \\
\text { by patients }\end{array}$ & $\begin{array}{l}\text { Patients' PC ratings correlate } \\
.51 \text { with spouses' EE } \\
\text { (Hooley \& Teasdale, 1989) }\end{array}$ & $\begin{array}{l}\text { Predicts relapse in unipolar } \\
\text { depression (Hooley \& Teasdale, } \\
\text { 1989) }\end{array}$ \\
\hline & & & & $\begin{array}{l}\text { Predicts anxiety after treatment in } \\
\text { panic and OCD patients } \\
\text { (Renshaw et al., 2003) }\end{array}$ \\
\hline & & & & $\begin{array}{l}\text { Predicts changes in symptom } \\
\text { severity in OCD and panic } \\
\text { patients (Chambless \& Steketee, } \\
1999 \text { ) }\end{array}$ \\
\hline & & & & $\begin{array}{l}\text { Predicts relapse in substance abuse } \\
\text { (Fals-Stewart et al., 2001) }\end{array}$ \\
\hline
\end{tabular}

Note. $\quad$ CFI $=$ Camberwell Family Interview $;$ FMSS $=$ Five Minute Speech Sample EOI $=$ Emotional Overinvolvement subscale; LEE $=$ Level of Expressed Emotion Scale; FAS = Family Attitude Scale; PC = Perceived Criticism; OCD = obsessive-compulsive disorder.

the CFI. However, he or she may be able to talk briefly about the patient in a manner that would permit an FMSS rating. In short, if an approximate EE rating is all that is required, the FMSS may be better than nothing at all. It is, however, a rather poor substitute, and it may be best suited for use in studies of disorders for which the effect size of EE is known to be relatively higher (e.g., mood disorders) and when the investigators plan to collect data on a large sample. Both of these factors will help compensate for the reliability problems inherent in the FMSS.

One relevant factor with regard to the questionnairebased assessments is who is available to complete the measure. Of the measures completed by relatives, the FAS shows early promise. Although more data are needed, the FAS correlates with EE as measured with the CFI and predicts relapse in patients with schizophrenia. The original 60-item LEE Scale also correlates quite well with the CFI and has predictive validity for psychotic disorders. However, neither of these instruments has been validated for any other diagnoses, so we cannot recommend them generally. The revised version of the LEE is still in need of further validation. We are unable to recommend its use as a measure of EE at this time.

Although it is far from clear exactly what ratings of PC actually measure, they have the advantage of being extremely quick to obtain. Of all the alternative measures of EE, PC has the advantage of speed and efficiency. It can be added to assessment batteries without any appreciable time burden. It also has some overlap with EE ratings obtained from the CFI. Most important, however, when completed by patients, it has demonstrated predictive validity for mood, anxiety, and substance abuse disorders. Although there are no indications to support its use in schizophrenia (for which the LEE or the FAS may be preferred), and with the caveat that PC ratings provide an estimate of only one aspect of EE (criticism), the measure of PC may have some general clinical utility. PC ratings are in no way a substitute for the CFI. However, in circumstances that call for a fast estimate of the affective climate in the family, the minimal time cost of a PC assessment appears to be greatly outweighed by its possible benefits as negative prognostic indicator. 


\section{References}

Asarnow, J. R., Goldstein, M. J., Tompson, M., \& Guthrie, D. (1993). One-year outcomes of depressive disorders in child psychiatric in-patients: Evaluation of the prognostic power of a brief measure of expressed emotion. Journal of Child Psychology and Psychiatry, 34, 129-137.

Baker, B., Helmes, E., \& Kazarian, S. S. (1984). Past and present attitudes of schizophrenics in relation to rehospitalization. British Journal of Psychiatry, 144, 263-269.

Barrowclough, C., Johnston, M., \& Tarrier, N. (1994). Attributions, expressed emotion, and patient relapse: An attributional model of relatives' response to schizophrenia illness. Behavior Therapy, 25, 67-88.

Beck, A. T., Ward, C. H., Mendelson, M., Mock, J., \& Erbaugh, J. (1961). An inventory for measuring depression. Archives of General Psychiatry, 4, 561-571.

Brown, G. W., Birley, J. L. T., \& Wing, J. K. (1972). Influence of family life on the course of schizophrenic disorders: A replication. British Journal of Psychiatry, 121, 241-258.

Brown, G. W., \& Rutter, M. (1966). The measurement of family activities and relationships: A methodological study. Human Relations, 19, 241-263.

Butzlaff, R. L., \& Hooley, J. M. (1998). Expressed emotion and psychiatric relapse. Archives of General Psychiatry, 55, 547552.

Chambless, D. L., Bryan, A. D., Aiken, L. S., Steketee, G., \& Hooley, J. M. (2001). Predicting expressed emotion: A study with families of obsessive-compulsive and agoraphobic outpatients. Journal of Family Psychology, 15, 225-240.

Chambless, D. L., \& Steketee, G. (1999). Expressed emotion and behavior therapy outcome: A prospective study with obsessivecompulsive and agoraphobic outpatients. Journal of Consulting and Clinical Psychology, 67, 658-665.

Cohen, S. Y., \& Wamboldt, F. S. (2000). The parent-physician relationship in pediatric asthma care. Journal of Pediatric Psychology, 25, 69-77.

Cole, J. D., \& Kazarian, S. S. (1988). The Level of Expressed Emotion Scale: A new measure of expressed emotion. Journal of Clinical Psychology, 44, 392-397.

Cole, J. D., \& Kazarian, S. S. (1993). Predictive validity of the Level of Expressed Emotion (LEE) Scale: Readmission follow-up data for 1, 2, and 5-year periods. Journal of Clinical Psychology, 49, 216-218.

Cook, W. L., \& Kenny, D. A. (2004). Application of the social relations model to family assessment. Journal of Family Psychology, 18, 361-371.

Cook, W. L., Kenny, D. A., \& Goldstein, M. J. (1991). Parental affective style risk and the family system: A social relations model analysis. Journal of Abnormal Psychology, 100, 492-501.

Daley, D., Sonuga-Barke, E. J. S., \& Thompson, M. (2003). Assessing expressed emotion in mothers of preschool AD/HD children: Psychometric properties of a modified speech sample. British Journal of Clinical Psychology, 42, 53-67.

Derogatis, L. R., Lipman, R. S., \& Covi, L. (1973). The SCL-90: An outpatient psychiatric rating scale-Preliminary Report. Psychopharmacology Bulletin, 9, 13-28.

Donat, D. C. (1996). Level of Expressed Emotion Scale scores and psychiatric rehospitalization. Psychiatric Rehabilitation Journal, 19, 57-60.

Donat, D. C., Geczy, B., Jr., Helmrich, J., \& LeMay, M. (1992). Empirically derived personality subtypes of public psychiatric patients: Effect on self-reported symptoms, coping inclinations, and evaluation of expressed emotion in caregivers. Journal of Personality Assessment, 58, 36-50.
Fals-Stewart, W., O’Farrell, T. J., \& Hooley, J. M. (2001). Relapse among married or cohabiting substance-abusing patients: The role of perceived criticism. Behavior Therapy, 32, 787-801.

Friedmann, M. S., \& Goldstein, M. J. (1993). Relatives' awareness of their own expressed emotion as measured by a self-report adjective checklist. Family Process, 32, 459-471.

Fujita, H., Shimodera, S., Izumoto, Y., Tanaka, S., Kii, M., Mino, Y., \& Inoue, S. (2002). Family Attitude Scale: Measurement of criticism in the relatives of patients with schizophrenia in Japan. Psychiatry Research, 110, 273-280.

Garner, D. M. (1991). Eating Disorder Inventory-2. Professional manual. Odessa, FL: Psychological Assessment Resources.

Gerlsma, C., \& Hale, W. W., III. (1997). Predictive power and construct validity of the Level of Expressed Emotion (LEE) scale: Depressed out-patients and couples from the general community. British Journal of Psychiatry, 170, 520-525.

Gerlsma, C., van der Lubbe, P. M., \& van Nieuwenhuizen, C. (1992). Factor analysis of the Level of Expressed Emotion Scale, a questionnaire intended to measure "perceived expressed emotion." British Journal of Psychiatry, 160, 385-389.

Hahlweg, K., Goldstein, M. J., Nuechterlein, K. H., Magana, A. B., Mintz, J., Doane, J. A., et al. (1989). Expressed emotion and patient-relative interaction in families of recent-onset schizophrenics. Journal of Consulting and Clinical Psychology, 57, $11-18$.

Hirshfeld, D. R., Biederman, J., Brody, L., Faraone, S. V., \& Rosenbaum, J. F. (1997). Associations between expressed emotion and child behavioral inhibition and psychopathology: A pilot study. Journal of the Academy of Child and Adolescent Psychiatry, 36, 205-213.

Hogarty, G. E., Anderson, C. M., Reiss, D. J., Kornblith, S. J., Greenwald, D. P., Javna, C. D., \& Madonia, M. J. (1986). Family psychoeducation, social skills training, and maintenance chemotherapy in the aftercare treatment of schizophrenia. Archives of General Psychiatry, 43, 633-642.

Hooley, J. M. (1986). Expressed emotion and depression: Interactions between patients and high- versus low-expressed-emotion spouses. Journal of Abnormal Psychology, 95, 3, 237-246.

Hooley, J. M. (1990). Expressed emotion and depression. In G. I. Keitner (Ed.), Depression and families (pp. 57-83). Washington, DC: American Psychiatric Press.

Hooley, J. M., \& Campbell, C. (2002). Control and controllability: Beliefs and behavior in high and low expressed emotion relatives. Psychological Medicine, 32, 1091-1099.

Hooley, J. M., \& Gotlib, I. H. (2000). A diathesis-stress conceptualization of expressed emotion and clinical outcome. Applied and Preventive Psychology, 9, 135-151.

Hooley, J. M., \& Licht, D. M. (1997). Expressed emotion and causal attributions in the spouses of depressed patients. Journal of Abnormal Psychology, 106, 298-306.

Hooley, J. M., \& Richters, J. E. (1991). Alternative measures of expressed emotion: A methodological and cautionary note. Journal of Abnormal Psychology, 100, 94-97.

Hooley, J. M., \& Teasdale, J. D. (1989). Predictors of relapse in unipolar depressives: Expressed emotion, marital distress, and perceived criticism. Journal of Abnormal Psychiatry, 98, 229 235.

Jacobsen, T., Hibbs, E., \& Ziegenhain, U. (2000). Maternal expressed emotion related to attachment disorganization in early childhood: A preliminary report. Journal of Child Psychology and Psychiatry, 41, 899-906.

Jarbin, H., Grawe, R. W., \& Hansson, K. (2000). Expressed emotion and prediction of relapse in adolescents with psychotic disorders. Nordic Journal of Psychiatry, 54, 201-205. 
Kavanagh, D. J., O’Halloran, P., Manicavasagar, V., Clark, D., Piatkowska, O., Tennant, C., \& Rosen, A. (1997). The Family Attitude Scale: Reliability and validity of a new scale for measuring the emotional climate of families. Psychiatry Research, 70, 185-195.

Kavanagh, D. J., \& Pourmand, D. (2005). Utility of the FAS in the prediction of psychotic relapse in people with schizophrenia and cannabis misuse. Manuscript in preparation.

Kazarian, S. S., Malla, A. K., Cole, J. D., \& Baker, B. (1990). Comparisons of two expressed emotion scales with the Camberwell Family Interview. Journal of Clinical Psychology, 46, 306309.

King, S., Lesage, A. D., \& Lalonde, P. (1994). Psychiatrists' ratings of expressed emotion. Canadian Journal of Psychiatry, 39, 358-360.

Kreisman, D. E., Simmens, S. J., \& Joy, V. D. (1979). Rejecting the patient: Preliminary validation of a self-report scale. Schizophrenia Bulletin, 2, 220-222.

Kurihara, T., Kato, M., Tsukahara, T., Takano, Y., \& Reverger, R. (2000). The low prevalence of high levels of expressed emotion in Bali. Psychiatry Research, 94, 229-238.

Leeb, B., Hahlweg, K., Goldstein, M. J., Feinstein, E., Mueller, U., Dose, M., \& Magaña-Amato, A. (1991). Cross-national reliability, concurrent validity, and stability of a brief method for assessing expressed emotion. Psychiatry Research, 39, 25-31.

Leff, J., Kuipers, L., Berkowitz, R., Eberlein-Fries, R., \& Sturgeon, D. (1982). A controlled trial of social intervention in the families of schizophrenic patients. British Journal of Psychiatry, $141,121-134$.

Leff, J. P., \& Vaughn, C. E. (1985). Expressed emotion in families. New York: Guilford Press.

Lopez, S. R., Hipke, K. N., Polo, A. J., Jenkins, J. H., Karno, M., Vaughn, C., \& Snyder, K. S. (2004). Ethnicity, expressed emotion, attributions, and course of schizophrenia: Family warmth matters. Journal of Abnormal Psychology, 113, 428-439.

Magaña, A. B., Goldstein, J. M., Karno, M., Miklowitz, D. J., Jenkins, J., \& Falloon, I. R. (1986). A brief method for assessing expressed emotion in relatives of psychiatric patients. Psychiatry Research, 17, 203-212.

Malla, A. K., Kazarian, S. S., Barnes, S., \& Cole, J. D. (1991). Validation of the Five-Minute Speech Sample in measuring expressed emotion. Canadian Journal of Psychiatry, 36, 297299.

Marom, S., Munitz, H., Jones, P. B., Weizman, A., \& Hermesh, H. (2002). Familial expressed emotion: Outcome and course of Israeli patients with schizophrenia. Schizophrenia Bulletin, 28, 731-743.

Marom, S., Munitz, H., Jones, P. B., Weizman, A., \& Hermesh, H. (2005). Expressed emotion: Relevance to rehospitalization in schizophrenia over 7 years. Schizophrenia Bulletin, 31, 751-758.

Miklowitz, D. J., Goldstein, M. J., Falloon, I. R., \& Doane, J. A. (1984). Interactional correlates of expressed emotion in the families of schizophrenics. British Journal of Psychiatry, 144, 482487.

Miklowitz, D. J., Wisniewski, S. R., Miyahara, S., Otto, M. W., \& Sachs, G. S. (2005). Perceived criticism from family members as a predictor of the 1-year course of bipolar disorder. Psychiatry Research, 136, 101-111.

Moore, E., \& Kuipers, E. (1999). The measurement of expressed emotion in relationships between staff and service users: The use of short speech samples. British Journal of Clinical Psychology, 38, 345-356.

Moulds, M. L., Touyz, S. W., Schotte, D., Beumont, P. J., Griffiths, R., Russell, J., \& Charles, M. (2000). Perceived expressed emotion in the siblings and parents of hospitalized patients with anorexia nervosa. International Journal of Eating Disorders, 27, 288-296.

Mueser, K. T., Bellack, A. S., \& Wade, J. H. (1992). Validation of a short version of the Camberwell Family Interview. Psychological Assessment, 4, 524-529.

Nugter, A. (1997). Family factors and interventions in recent onset schizophrenia. Unpublished doctoral dissertation, Universiteit van Amsterdam, Amsterdam.

O'Farrell, T. J., Hooley, J. M., Fals-Stewart, W., \& Cutter, H. S. G. (1998). Expressed emotion and relapse in alcoholic patients. Journal of Consulting and Clinical Psychology, 66, 744-752.

Okasha, A., El Akabawi, A. S., Snyder, K. S., Wilson, A. K., Youssef, I., \& El Dawla, A. S. (1994). Expressed emotion, perceived criticism, and relapse in depression: A replication in an Egyptian sample. American Journal of Psychiatry, 151, 10011005.

Peris, T. S., \& Baker, B. L. (2000). Applications of the expressed emotion construct to young children with externalizing behavior: Stability and prediction over time. Journal of Child Psychology and Psychiatry, 41, 457-462.

Phillips, M. R., \& Xiong, W. (1995). Expressed emotion in Mainland China: Chinese families with schizophrenic patients. International Journal of Mental Health, 24(3), 54-75.

Pourmand, D. (2005). Expressed emotion as predictor of relapse in patients with comorbid psychosis and substance use disorder. Unpublished doctoral thesis, University of Queensland, Brisbane, Queensland, Australia.

Renshaw, K. D., Chambless, D., \& Steketee, G. (2001). Comorbidity fails to account for the relationship of expressed emotion and perceived criticism to treatment outcome in patients with anxiety disorders. Journal of Behavior Therapy and Experimental Psychiatry, 32, 145-158.

Renshaw, K. D., Chambless, D. L., \& Steketee, G. (2003). Perceived criticism predicts severity of anxiety symptoms after behavioral treatment in patients with obsessive-compulsive disorder and panic disorder with agoraphobia. Journal of Clinical Psychology, 59, 411-421.

Riso, L. P., Klein, D. N., Ouimette, P. C., Anderson, R. L., \& Lizardi, B. (1996). Convergent and discriminant validity of perceived criticism from spouses and family members. Behavior Therapy, 27, 129-137.

Shimodera, S., Mino, Y., Fujita, H., Izumoto, Y., Kamimura, N., \& Inoue, S. (2002). Validity of a five-minute speech sample for the measurement of expressed emotion in the families of Japanese patients with mood disorders. Psychiatry Research, 112, 231-237. Shimodera, S., Mino, Y., Inoue, S., Izumoto, Y., Kishi, Y., \& Tanaka, S. (1999). Validity of a Five-Minute Speech Sample in measuring expressed emotion in the families of patients with schizophrenia in Japan. Comprehensive Psychiatry, 40, 372-376.

Simoneau, T. L., Miklowitz, D. J., \& Saleem, R. (1998). Expressed emotion and interactional patterns in the families of bipolar patients. Journal of Abnormal Psychology, 107, 497-507.

Tanaka, S., Mino, Y., \& Inoue, S. (1995). Expressed emotion and the course of schizophrenia in Japan. British Journal of Psychiatry, 167, 794-798.

Tattan, T., \& Tarrier, N. (2000). The expressed emotion of case managers of the seriously mentally ill: The influence of expressed emotion on clinical outcome. Psychological Medicine, 30, 195-204.

Thompson, M. C., Goldstein, M. J., Lebell, L. B., Mintz, L. I., Marder, S. R., \& Mintz, J. (1995). Schizophrenic patients' perceptions of their relatives' attitudes. Psychiatry Research, 57, $155-167$. 
Uehara, T., Yokoyama, T., Goto, M., \& Ihda, S. (1996). Expressed emotion and short-term treatment outcome of outpatients with major depression. Comprehensive Psychiatry, 37, 299-304.

Uehara, T., Yokoyama, T., Nakano, Y., Ihda, S., Goto, M., Komura, N., \& Toyooka, K. (1997). Characteristics of expressed emotion rated by the five minute speech sample and relationship with relapse of outpatients with schizophrenia. Clinical Psychiatry, 39, 31-37.

Van Humbeeck, G., Van Audenhove, C., \& Declercq, A. (2004). Mental health, burnout and job satisfaction among professionals in sheltered living in Flanders: A pilot study. Social Psychiatry and Psychiatry Epidemiology, 39, 569-575.

Van Humbeeck, G., Van Audenhove, C., De Hert, M., Pieters, G., \& Storms, G. (2002). Expressed emotion: A review of assessment instruments. Clinical Psychology Review, 22, 321-341.

Wamboldt, F. S., O'Connor, S. L., Wamboldt, M. Z., Gavin, L. A., \& Klinnert, M. D. (2000). The five minute speech sample in children with asthma: Deconstructing the construct of expressed emotion. Journal of Child Psychology and Psychiatry and Allied Disciplines, 41, 887-898.

Yan, L. J., Hammen, C., Cohen, A. N., Daley, S. E., \& Henry, R. M. (2004). Expressed emotion versus relationship quality variables in the prediction of recurrence in bipolar patients. Journal of Affective Disorders, 83, 199-206.

Received April 12, 2005

Revision received July 6, 2005

Accepted July 26, 2005

\section{American Psychological Association SUBSCRIPTION ClaImS INFORMATION}

Today's Date:

We provide this form to assist members, institutions, and nonmember individuals with any subscription problems. With the appropriate information we can begin a resolution. If you use the services of an agent, please do NOT duplicate claims through them and directly to us. PLEASE PRINT CLEARLY AND IN INK IF POSSIBLE.

\begin{tabular}{llll}
\hline PRINT FULL NAME OR KEY NAME OF INSTITUTION & & \\
\hline ADDRESS & & & \\
\hline CITY & & & \\
\hline
\end{tabular}

YOUR NAME AND PHONE NUMBER

TITLE

\section{MEMBER OR CUSTOMER NIMBER (MAY BEFOUND ON ANY PAST ISSUE LABEL)} DATE YOUR ORDER WAS MAILED (OR PHONED)

\section{PREPAID _ CHECK _ CHARGE}

CHECK/CARD CLEARED DATE:

(If possible, send a copy, fromt and back, of your cancelled check to help us in our research of your clainn.

ISSUES: __ MISSING _ DAMAGED

VOLUME OR YEAR NUMBER OR MONTH

Thank you. Once a claim is received and resolved, delivery of replacement issues routinely takes 4-6 weeks.

(TO BE FILLED OUT BY APA STAFF)

DATE RECEIVED:

ACTION TAKEN:

STAFF NAME:
DATE OF ACTION:

INV. NO. \& DATE:

LABEL NO. \& DATE:

Send this form to APA Subscription Claims, 750 First Street, NE, Washington, DC 20002-4242

PLEASE DO NOT REMOVE. A PHOTOCOPY MAY BE USED. 